\title{
Features of the Oceanological Values Fields in the Sivash Bay (The Sea of Azov)
}

\author{
P. D. Lomakin \\ Marine Hydrophysical Institute of RAS, Sevastopol, Russian Federation \\ p_lomakin@mail.ru
}

\begin{abstract}
Purpose. The study is aimed at revealing the structural regularities and variability of the fields of temperature, salinity, the colored dissolved organic matter and total suspended matter concentrations, and also the factors that form them in the Sivash Bay. Besides, the results obtained are to be compared with the already known features of the fields of the values under investigation which are typical of the Azov-Black Sea coastal zone; and the response in the considered fields to the North Crimean Canal damming is to be assessed.

Methods and Results. Based on the data of 8 expeditions carried out by Marine Hydrophysical Institute in 2013-2016, the structural regularities and variability of the fields of temperature, salinity, the colored dissolved organic matter and total suspended matter concentrations, and the factors that form the fields of these values in the Sivash Bay were revealed. The quantitative indicators of changes in the fields of the considered values, which arose after the North Crimean Canal was dammed, are represented.

Conclusions. In the region under study, a number of constantly acting factors that determine formation of special, not typical of the coastal area features of the oceanological values fields are identified, namely: the influence of the Azov Sea and the North Crimean Canal waters, the rivers inflowing to the water area of the Sivash western coast, the isolated lakes, the swampy shallow bays and the isolated relatively deep parts of the coastline. Three y ears after the North Crimean Canal was dammed, in the northwestern Sivash salinity increased by 20 PSU. The opinion that Sivash is not a typical sea bay, but a connected with the Azov Sea reservoir with the signs of a salt swamp is confirmed.
\end{abstract}

Keywords: temperature, salinity, colored dissolved organic matter, total suspended matter, Sivash Bay, North Crimean Canal, Sea of Azov

Acknowledgments: the work was carried out within the framework of the state task on topic No. 0827-2019-0004 "Comprehensive interdisciplinary studies of oceanological processes which determine functioning and evolution of ecosystems in the coastal zones of the Black and Azov seas".

For citation: Lomakin, P.D., 2021. Features of the Oceanological Values Fields in the Sivash Bay (The Sea of Azov). Physical Oceanography, [e-journal] 28(6), pp. 647-659. doi:10.22449/1573160X-2021-6-647-659

DOI: $10.22449 / 1573-160 \mathrm{X}-2021-6-647-659$

(C) P. D. Lomakin, 2021

(C) Phy sical Oceanography, 2021

\section{Introduction}

Coastal swamplands are valuable ecosystems that provide habitat for numerous marine and terrestrial animal and plant species, improve water quality, stabilize the coastline, prevent coastal flooding, and assimilate atmospheric carbon [1-5]. Apparently, the Sivash bay (lake) is a unique water body of the Azov-Black Sea basin. It is characterized by extremely high salinity and a special hydrological regime, with signs of a sea and salina, ans is insufficiently studied from the point of view of oceanology, can be attributed to such lands and ecosystems.

The Sivash is a narrow isolated shallow bay located along the western coast of the Sea of Azov. It is separated from the sea by a meridional oriented spit - 
the Arabatskaya Strelka. In the northeastern part, near Genichesk, the Sivash is connected to the Sea of Azov by the Tonkiy and Arabatskiy straits. Sometimes the Sivash is called the Rotten Sea, which includes a system of lagoons and swamps separating the Crimean Peninsula from the mainland [6] (Fig. 1).

The present paper is aimed to reveal the regularities of the structure and variability of the fields of temperature, salinity, concentration of colored dissolved organic matter (DOM) and concentration of total suspended matter (TSM) in the Sivash Bay; to determine the DOM sources entering the bay, as well as the places of its deposition; to calculate and analyze the correlation dependence of the DOM content on salinity for the Sivash and the Sea of Azov; to estimate the temporal variations in the fields of these values, which are caused by the North Crimean Canal overlap.

\section{Initial data and research me thods}

For the analysis, the data from 8 expeditions of Marine Hydrophysical Institute in the Lake Sivash coastal area in 2013-2016 is used. In 2013, the expeditions were completed before the North Crimean Canal closure (Fig. 1).

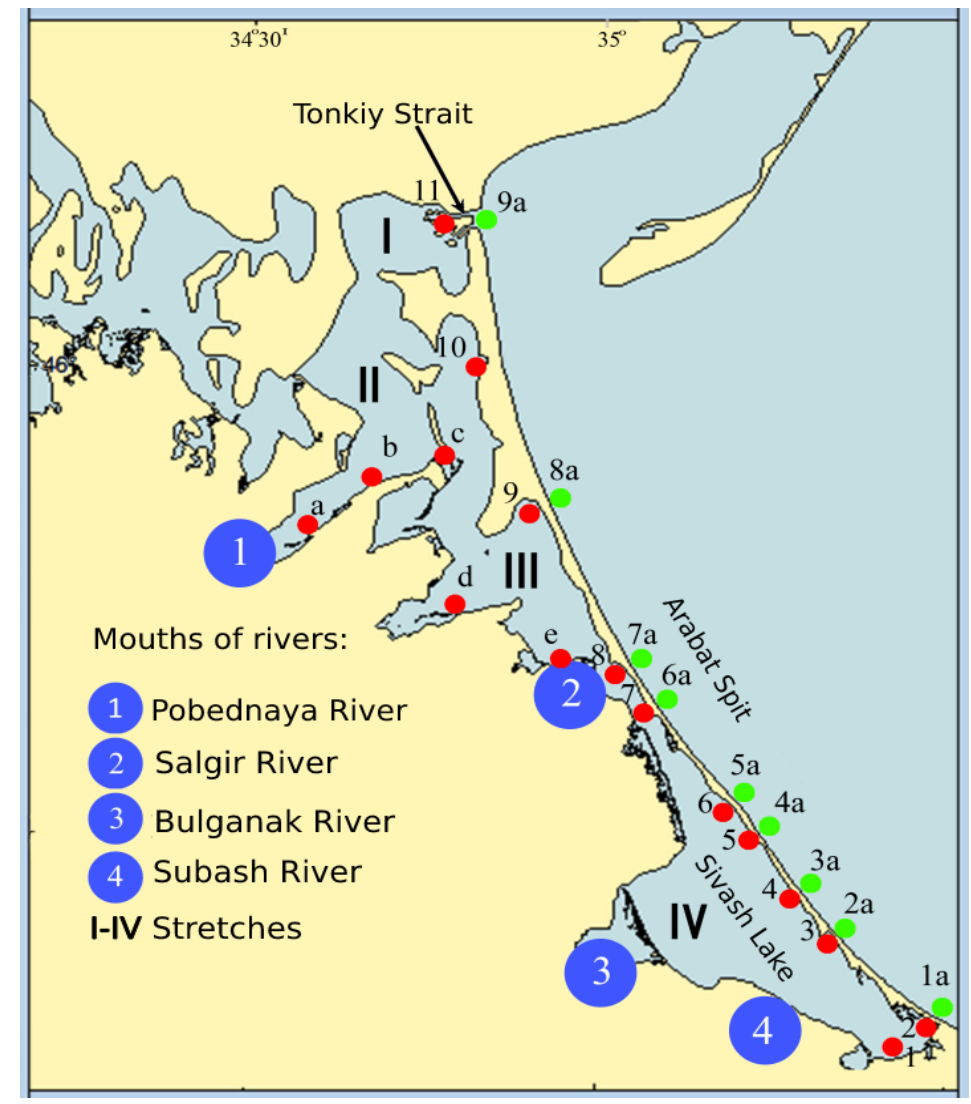

F i g. 1. The investigated water area with a grid of stations: 1-11 are the stations along the western coast of the Arabat Spit; 1a-9a are the stations in the Sea of Azov 
During the first expedition (June 2013) in the eastern part of the Sivash, along the Arabat Spit (112 km long), coastal observations (including 11 stations) were carried out from the southernmost point (the Lvov khutor) to the Tonkiy Strait in the north. Similar observations (9 stations) were carried out along the eastern coast of the Arabat Spit in the Sea of Azov. In October 2013 and in June and October 2014-2016 observations were carried out in the northwestern part of the region under study at 5 stations. The stations were selected according to the physical, geographical and hydrological features inherent in the coastal zone of the Sivash. Station $a$ was located in the riverine part of the mouth of the Pobednaya River, stations $b$ and $c$ - in the marine area of the mouths of the Pobednaya and Salgir rivers, stations $d$ and $e$ - between the swampy estuaries of these rivers, along an open section of the coastline (Fig. 1).

At all stations, the water temperature, salinity, TSM concentration and the colored DOM content were measured. These parameters were synchronously recorded using the Kondor optical biophysical probing complex (autonomous multiparameter hydrobiophysical submersible complex, URL: http://ecodevice.com.ru/ecodevicecatalogue/multiturbidimeterkondor).

The TSM and DOM content determination is based on optical methods implemented in the Kondor measuring complex. The fluorescent component of DOM - a colored dissolved organic matter (fDOM) was considered. The dimension of this quantity is presented in calibration units - quinine sulfate (QSU) [7, 8].

Since the depth range did not exceed $1 \mathrm{~m}$, the probe was used in "selected" mode. Therefore, the device sensors were placed in a vessel with selected water samples.

\section{Discussion of the results}

Below some of the physical-geographical and morphometric features of the region under study, information about which was used in the interpretation of the data of expeditionary studies are considered.

The Sivash banks are mostly low, gentle, marshy, and salt-covered in summer. The bottom is a layer of silt up to $5 \mathrm{~m}$ thick or more. Its water surface is divided by four relatively isolated reservoirs - stretches. Stretch I, II and III are delimited by shoals, chains of islets, spits and capes. The boundary between stretches III and IV is represented by the narrowest section of the considered water area the Shokalinskiy narrowing (Fig. 1).

The coastal zone of the Sivash is distinguished by a variety of landscapes and morphometric features that are not characteristic of the open coast of the AzovBlack Sea basin (Fig. 2). This determines the special structure of the fields of oceanological elements in the coastal waters of the Sivash Bay, characterized by pronounced inhomogeneities [9, 10].

A number of constantly acting factors that contribute to the formation of special properties of fields of oceanological quantities in the studied water area was identified. These are the largest $(\sim 100 \mathrm{~km})$ factors. Their impact extends to the entire bay. They are associated with the influence of the Sea of Azov waters, penetrating into the Sivash through the Tonkiy and Arabatskyi straits, as well as the waters of the North Crimean canal, which was put into operation in 1971 and closed in 2014. 


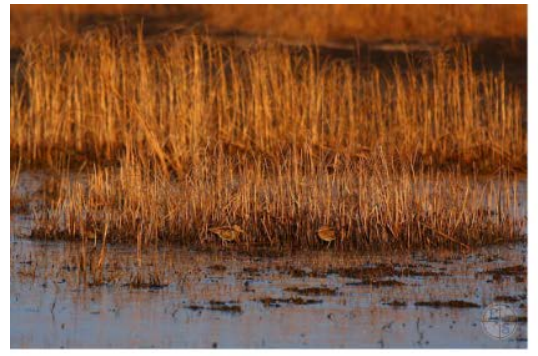

a

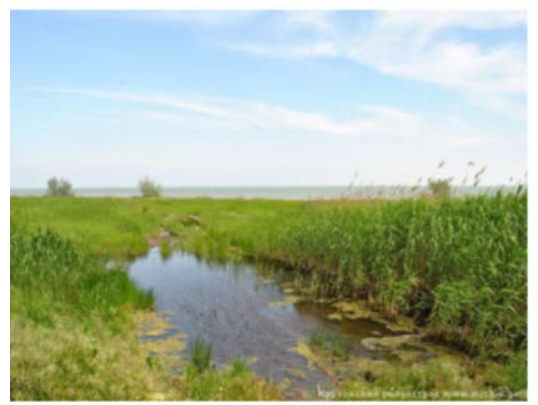

$c$

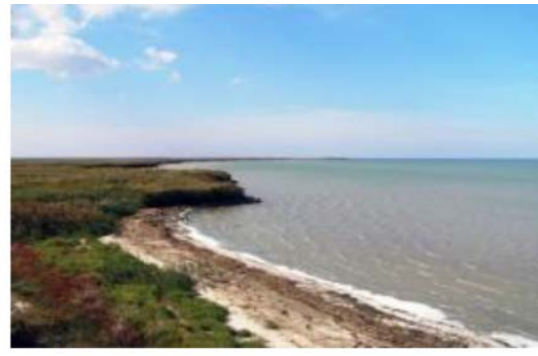

$b$

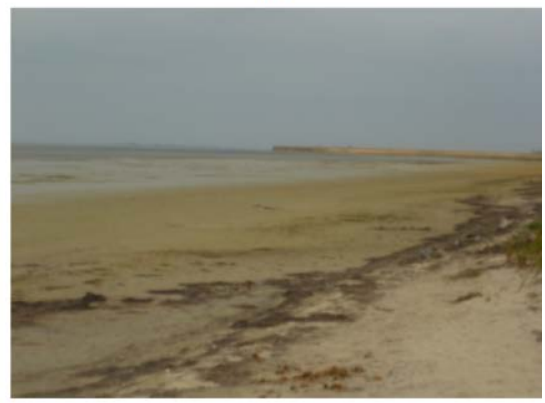

$d$

F i g. 2. Typical areas of the Sivash Bay coast: $a$-swampy river delta off the Sivash western coast; $b$ - part of the western coast with a relatively deep shell bottom; $c$ - lake in the floodplains of the Arabat Spit; $d-$ coastal water area of the reach near the Arabat Spit (URL: https://www.photoukraine.com/russian/articles?id=242)

Small-scale (from $\sim 100 \mathrm{~m}$ to $10-30 \mathrm{~km}$ ), but significant factors can be attributed to the rivers flowing into the water area along the western bank of the Sivash; isolated lakes in flooded areas; swampy shallow bays located on the periphery of the reaches and isolated sections of the coastline with a relatively deep coast.

In terms of morphometric characteristics and hydrological regime, the western coast of the Sivash significantly differs from the eastern one. The Crimean rivers Pobednaya, Salgir, Bulganak, Subash flow into the water area of the western part of the Sivash Bay [9] (Fig. 1). Boggy and overgrown with dense thickets of reeds and willows, the mouths of these rivers and the adjacent coastal areas are vast salt bogs. They are shallow $(0.1-0.3 \mathrm{~m})$, with banks and bottom covered with a black silt layer (Fig. 2, a).

The swamps of the western Sivash are divided by steep, mostly clay rocky and covered with steppe vegetation coastline sections. The coast here is relatively deep $(0.5-0.8 \mathrm{~m})$ with a shell bottom (Fig. 2, b).

The eastern coast of the Sivash Bay (western coast of the Arabat Spit), along which observations were made in June 2013 (Fig. 1), is different from the western coast in terms of physical and geographical conditions. It is not swampy, the banks and the bottom here are mostly sandy-shell [10].

The eastern coast of the Sivash is characterized by two coastal areas with different physical and geographical conditions and the properties of the fields of the analyzed quantities. The shores of the southern narrow (width $\sim 300 \mathrm{~m}$ ) part of 
the Arabat Spit are covered with dense thickets of reeds (floodplain). Further to the north, along the coast of the wide $(7.5 \mathrm{~km})$ part of the Arabatskaya Strelka, there is a shallow bay, which is the eastern periphery of stretch II (Fig. 2, $d$ ), and on the eastern periphery of the water area of the northernmost stretch $\mathrm{I}$, there are the Tonkiy and Arabatskiy straits (Fig. 1).

The floodplains near the southern part of the Arabat Spit are $\sim 0.1-1.5 \mathrm{~km}$ wide. Here, in thickets of reeds, there is a number of small lakes $0.8-1.5 \mathrm{~m}$ deep and several tens to $\sim 100 \mathrm{~m}$ in diameter, isolated to varying degrees from the coast and the main water surface (Fig. 2, $c$ ). These lakes or some of them are probably former sand pits. These are the deepest, up to $1.5 \mathrm{~m}$, places of the entire studied coastal zone, distinguished by the special properties of the analyzed quantities.

Water temperature is the most variable in space and time (of all considered) environmental parameter. The isolation of the coastal areas, their different depths, bottom color, albedo and absorption capacity of solar radiation under conditions of limited horizontal exchange cause significant spatial inhomogeneities in the water temperature field near the Sivash coast.

During the entire observation period on the western coast of the Sivash, in a bay with a relatively deep coast and a shell bottom, between the mouths of the Pobednaya and Salgir rivers (station $d$ ), a local temperature minimum was constantly recorded. Due to the high albedo and greater depth, the water temperature here was $0.4-2.3^{\circ} \mathrm{C}$ lower than in the shallow-water estuaries covered with black silt to the north (station $b$ ) and south (station $e$ ) (Fig. 1).

On the eastern coast of the Sivash, as a result of the different absorptive capacity of solar radiation, two sections of the coastline with different temperature regimes - floodplains in the south with a low water temperature of $24-28^{\circ} \mathrm{C}$ and an overheated coastal zone of reaches near the northern part of the Arabat Spit with a high water temperature of $32-35^{\circ} \mathrm{C}$ (according to observations in June 2013, Fig. 1, 2) were distinguished.

Daily water temperature fluctuations in the coastal waters of the Sivash are more intense than in the coastal waters. In summer, the range of daily fluctuations reached $4-6^{\circ} \mathrm{C}$. The temperature minimum was recorded in the morning (06:0007:00), the maximum - in the afternoon (14:00-15:00). According to [11], in the Azov and Black Seas, daily fluctuations in water temperature are less significant, their maximum range of $2-3^{\circ} \mathrm{C}$ was observed at the $0.2 \mathrm{~m}$ horizon in the spring-summer period.

A qualitative analysis of the available small sample of observations showed that the temporal variations in water temperature contained interannual, seasonal, synoptic and diurnal components. In June - July, the coastal waters of the Sivash were characterized by high temperatures: in 2013 it varied in the range of 24.3$35.2^{\circ} \mathrm{C}$, in 2016 it was characterized by relatively low values of $25.0-27.9^{\circ} \mathrm{C}$. In October 2014 and 2016 the corresponding indicators were $16.1-17.8^{\circ} \mathrm{C}$ and $8.4-$ $8.9^{\circ} \mathrm{C}$.

Salinity and fDOM concentration fields. In the coastal waters of the oceans and seas, salinity and fDOM are interrelated quantities with conservative properties. They are considered as good indicators of the continental runoff spread in open water areas [12-17]. Therefore, the analysis of the fields of these quantities is carried out in conjunction. 
Fig. 3 shows the fields of the horizontal distribution of salinity and fDOM content for the studied water area, which were obtained from the data of two expeditions carried out in June and October 2013, before the North Crimean Canal closure. The validity of combining the empirical data obtained with a difference of four months into one scheme is based on the property of conservatism, which is inherent in both salinity and fDOM [12]. When constructing the schemes, the observational data along the Arabat Spit coast at two stations (stations 3 and 10, Fig. 4), which differed in extreme values and fell out of the general trend of an increase in salinity and fDOM concentration in a southerly direction, were excluded. An analysis of these local features is given below.

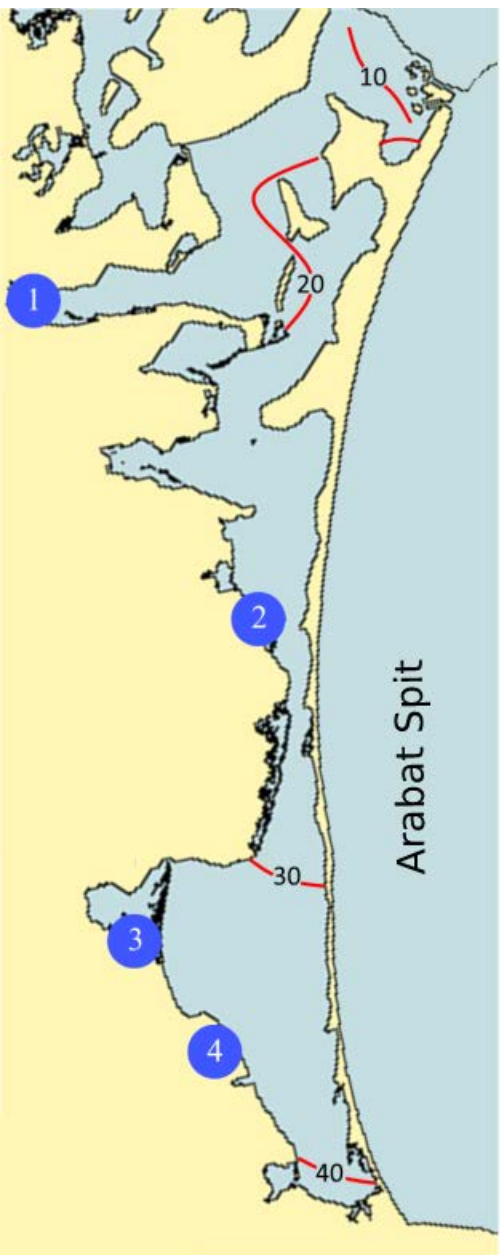

$a$

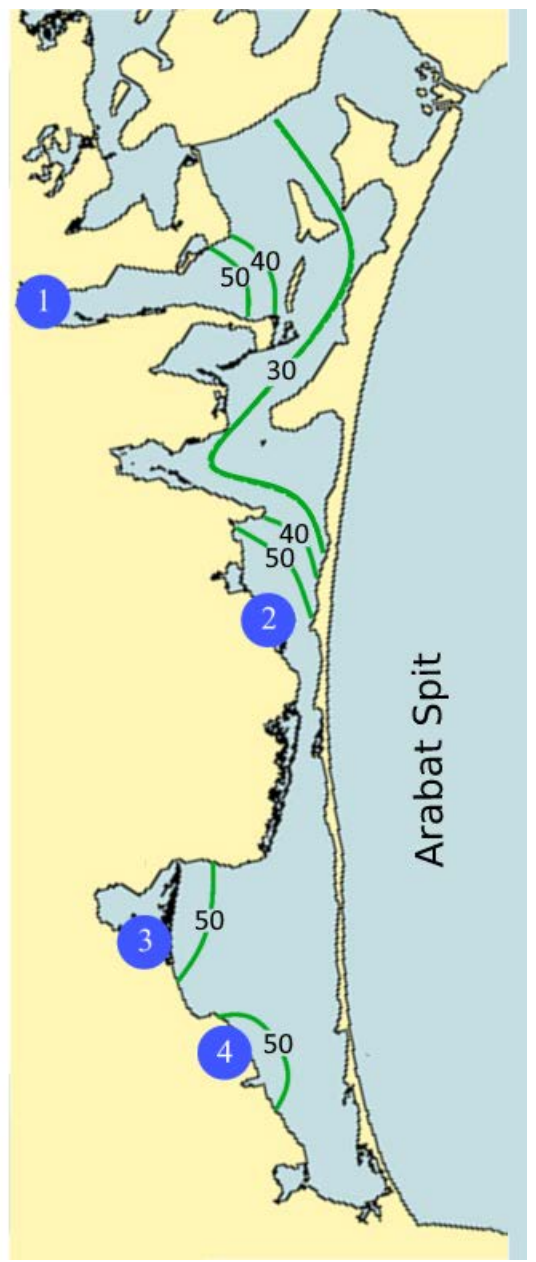

$b$

F i g. 3. Distribution of salinity, PSU ( $a$ ) and content of fDOM, QSU (b) on the surface of the Sivash Bay in June - October, 2013 before the North Crimean Canal was dammed 


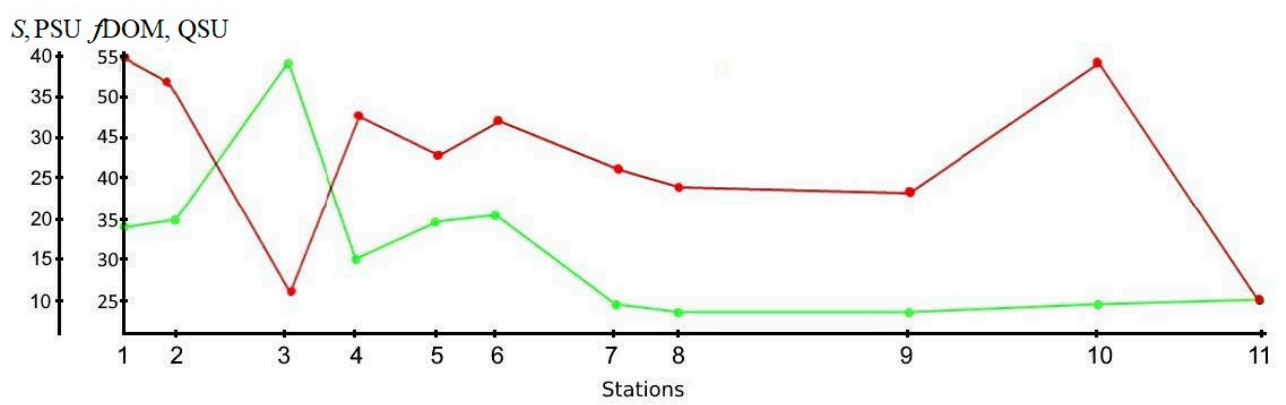

F i g. 4. Distribution of salinity, PSU (red line) and concentration of fDOM, QSU (green line) along the western coast of the Arabat Spit in June, 2013

Excluding the singular points with extrema of salinity and fDOM concentration, "smooth" distributions of the studied values on the surface were obtained. They are easy to interpret and, apparently, adequately reflect the state of the waters of the bay before the North Crimean canal closure. They also give possibility to identify the main factors and sources that form the structure of the considered fields in the Sivash.

Before the North Crimean Canal closure, salinity in the Sivash increased from north to south from 10 PSU near the Tonkiy Strait to 40 PSU in the area of the most remote isolated stretch IV. The maximum freshening (10-20 PSU, Fig. 3, a) was experienced in the northwestern part of the bay, where the Dnieper water discharge point was located. The western bank of the Sivash was freshened with irrigation water, which was drained from irrigated lands, rice paddies and ponds of five large fish farms.

One of the salinity field features in the Sivash Bay is the absence of signs of a freshening effect in river estuaries. For the entire period, in the mouths of the Pobednaya and Salgir rivers, in the immediate vicinity of the reed wall, lenses of freshened water, typical of the mouths of rivers flowing into the sea, were not observed. From the mouth of the Pobednaya River to the Salgir mouth, salinity increased gradually (Fig. 3,a).

At the same time, the influence of the runoff of these rivers was clearly pronounced near the western coast of the Sivash in the fDOM concentration field. Below it is shown that the river runoff is the main source providing the dissolved organic matter input into the Sivash, which settles in the estuarine zones in the west of the studied water area, forming the main maxima (52-57 QSU) in the large-scale field of this substance concentration. The minimum concentration of the background field fDOM is typical for the western part of the Sivash Bay. In the Tonkiy Strait and the shallow bay of stretch II adjacent to it from the south, as in the adjacent water area of the Sea of Azov, the fDOM content did not exceed 25-27 QSU (Fig. 3, b). This is shown in Fig. 4 in detail.

In October 2013, at the sea edge of the Pobednaya River mouth (station $b$ ) and the Salgir River mouth (station $f$ ), in the immediate vicinity of the reed wall, the absolute maxima of this value concentration were observed in the Sivash Bay. It was 56 and 52-57 QSU, respectively. In relatively deep areas between the mouths of the Pobednaya and Salgir rivers, the fDOM content was decreased, 
37-40 QSU (Fig. 1; 3, b). A similar structural feature, but with a lower background concentration of fDOM, persisted in 2014-2016.

According to data for October 2013, at the mouth of the Pobednaya River in the fDOM content field, a powerful frontal section with a length of $\sim 7 \mathrm{~km}$ with a concentration at the boundaries of 510 QSU (station $a$ ) and 56 QSU (station $b$ ) and a horizontal gradient of 65 QSU/km was monitored. Judging by the difference in fDOM concentration at the front boundaries, at the Pobednaya River mouth settles up to $90 \%$ of this substance contained in river water.

An abrupt decrease in the fDOM content at the boundaries of the Pobednaya River mouth is one of the main features of a natural marginal filter - a barrier zone on which a significant amount of suspended and dissolved substances of both natural and anthropogenic origin, contained in river water, is deposited [18-21]. Apparently, marginal filters with similar parameters exist in the mouths of other rivers (Salgir, Bulganak and Subash), flowing into the water area along the western coast of the Sivash Bay. Unfortunately, there are no observations in the riverine part of their mouths.

Observations carried out in the northwestern part of the Sivash in 2014-2016 made it possible to estimate changes in the fields of the analyzed quantities, which were caused by the overlap of the North Crimean Canal in June 2014. The trend of a sharp increase in salinity in the waters of the northwestern part of the Sivash was already discovered according to the results of the first expedition after the canal closure in June 2014. The average salinity for this part of the Sivash water area in 2014 was 31 PSU. Compared to 2013, it increased by 14 PSUs. In 2015, the rate of salinity increase fell to 5 PSU per year, and by the end of this year it reached 36 PSU. In 2016, the salinity growth slowed down to $\sim 1$ PSU per year. Three years after the North Crimean Canal closure, the salinity of the waters in the area under consideration increased from 17 to 37 PSU.

After the channel was closed, which was accompanied by an increase in salinity, the average concentration of $\mathrm{fDOM}$ in the northwestern Sivash, equal to 40-50 QSU in 2013, decreased to 24-36 QSU.

Below we return to the series of observations along the western coast of the Arabat Spit (Fig. 4). The information from station 3 and 10 was used to construct large-scale background salinity and concentration fDOM fields.

The salinity and concentration fDOM distribution in the area under consideration reveals the main regularity of the meridional structure of the fields of these characteristics in the Sivash Bay. If the data of station 3 and 10 is not taken into account, an increase in both values is seen from the Tonkiy Strait to the southern area of the bay (stretch IV, Fig. 1).

Extremes recorded at station 3 and 10 are not accidental. They reflect the real state of waters of special sections of the coastline and confirm the variety of properties of fields of oceanological quantities in the Sivash Bay.

At station 3, made in the floodplains near Arabatskaya Strelka in one of the isolated lakes (Fig. 1; 2, c), the minimum salinity of 11 PSU and the maximum concentration fDOM 55 QSU were noted against the general background. Salinity at the nearby stations was 37 and 33 PSU, fDOM concentration was 35 and 31 QSU (Fig. 4). 
The low salinity recorded in the lake may be associated with intense rains that preceded and accompanied the expeditionary research. The lakes are also likely to be fed by groundwater [10]. The high fDOM concentration in lakes is due to the special hydrochemical and hydrobiological conditions inherent in such rare water bodies.

Station 10 is located on the coast of a shallow (0.1-0.2 m) flat-bottomed bay stretched in the meridional plan, which is bounded in the south by a cape, in the north by the Genicheskiy Kut peninsula, and in the west by a chain of islands and shoals (stretch II, Fig. 1; 2, d).

As a result of the high absorptive capacity of solar radiation, with a low albedo (muddy shores and the bottom of a dark brown color), the waters of the bay are maximally warmed up and saline. The water temperature in June reached $33-35^{\circ} \mathrm{C}$. Due to local intense evaporation, the water salinity was 10-29 PSU higher than that of the nearby stations (Fig. 4).

Despite the anomalously high values of thermohaline indices, the fDOM concentration in the bay waters was 25 QSU and did not differ from the background content of the analyzed substance in coastal waters near the northeastern part of the Arabatskaya Strelka (station 7-11, Fig. 4).

The vectors of the horizontal gradient in the fields of both values had a wellpronounced southward-directed component, which at a qualitative level indicates the absence of a negative relationship between salinity and concentration fDOM in the Sivash waters, which is characteristic of the marine environment (Fig. 3, 4).

At a quantitative level, this relationship is demonstrated in Fig. 5, $a$. It shows the straight line of the correlation dependence fDOM $(S)$, calculated from the results of observations along the Arabat Spit for the Sivash in June 2013. Station 3 and 10 data, reflecting special properties on local sections of the coastline, was excluded from the original sample (Fig. 4).

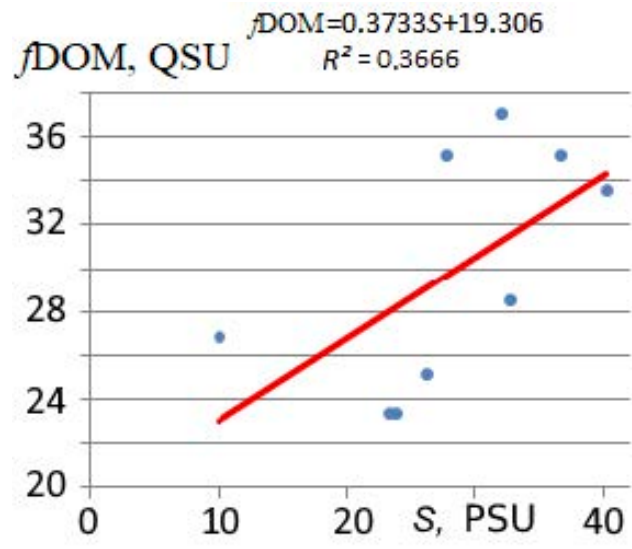

$a$

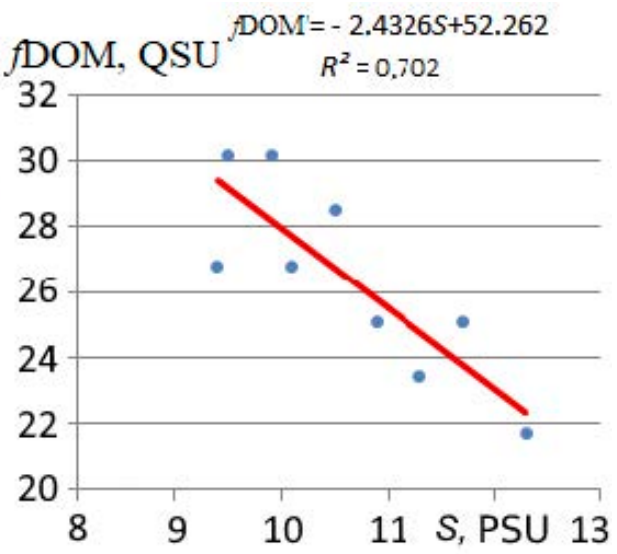

$b$

F i g. 5. Graphs of correlation dependence of the fDOM concentration on salinity: $a$ - in the Sivash Bay; $b$ - in the Sea of Azov 
It can be seen that in the Sivash Bay waters there is a direct correlation between salinity and fDOM concentration, which is not typical for the sea, with a coefficient $\mathrm{R}=0.61$ (Fig. 5, $a$ ).

In the Sea of Azov, the correlation relationship $\operatorname{fDOM}(S)$ is inverse and close, $\mathrm{R}=-0.84$. Along the Arabat Spit in the Sea of Azov, salinity increased southward from 9.4 PSU in the area of the Tonkiy Strait to 12.2 PSU in the south of the sea, while the fDOM concentration of decreased from 27-30 QSU to 22 QSU (Fig. 5, b).

The freshened continental runoff of shelf waters of the oceans and seas is characterized by a close inverse correlation dependence of the concentration of dissolved organic matter on salinity and $\operatorname{fDOM}(S)$ with the coefficient $\mathrm{R}=-0.68 \ldots-0.95$ [12-18]. That is, in the Sea of Azov, the values under consideration are related by a dependence typical for the marine environment, while for the waters of the Sivash the correlation dependence $\mathrm{fDOM}(S)$ is qualitatively different.

TSM concentration field. The Sivash waters are distinguished by the unusual properties of the TSM concentration field. This value is mainly determined by shallow depths, the nature of the soil and the wind. Under conditions of low wind and calm weather, the bay waters are transparent and contain 1-2 mg/L of TSM. This value field reacts to an increase in the wind very quickly; in a moderate wind, the TSM concentration reaches $40-42 \mathrm{mg} / \mathrm{l}$, and the waters acquire a brown color. For comparison: according to MHI observations, the typical TSM concentration in the Black Sea waters near the coast of Crimea with weak and moderate winds doesn't exceed $0.8-2.0 \mathrm{mg} / \mathrm{l}$.

\section{Conclusion}

Based on the data of 8 expeditions carried out by Marine Hydrophysical Institute in 2013-2016, the factors that form the fields of temperature, salinity, fDOM and TSM concentration in the Sivash Bay were identified. The regularities of the structure of the fields of these quantities are analyzed, the correlation dependence between salinity and fDOM content is considered. The response in the salinity and fDOM concentration fields to the North Crimean Canal closure was tracked.

In the region under study, a number of constantly acting factors that determine the formation of special, not typical for coastal sea areas, properties of fields of oceanological quantities, was identified. These include: the influence of the Sea of Azov waters, penetrating into the Sivash through the Tonkiy and Arabatskiy straits; the North Crimean Canal waters (until the moment of its closure); rivers flowing into the water area along the western bank of the Sivash; isolated lakes in flooded areas; swampy shallow bays located on the periphery of the reaches and isolated relatively deep sections of the coastline. The scale of the impact of the detected factors in the fields of the considered values is from $100 \mathrm{~m}$ to the size of the entire water area of the Sivash Bay, 10-100 km.

The water temperature field was characterized by significant spatial heterogeneity. On the western coast of the Sivash, in a bay with a relatively deep coast and a shell bottom, between the mouths of the Pobednaya and Salgir rivers, a local temperature minimum was constantly recorded. Due to the high albedo and greater depth, the water temperature here was $0.4-2.3^{\circ} \mathrm{C}$ lower than 
the temperature of the shallow-water estuaries covered with black silt located to the north and south. On the eastern coast of the Sivash, as a result of different absorptive capacity of solar radiation, two sections of the coastline with different temperature regimes were distinguished. They are floodplains in the south with a low water temperature of $24-28^{\circ} \mathrm{C}$ and an overheated coastal zone of stretches near the northern part of the Arabat Spit with a high water temperature of $32-35^{\circ} \mathrm{C}$. Daily fluctuations in water temperature in the coastal waters of the Sivash are more intense than in the coastal waters. In summer, their range reached $4-6^{\circ} \mathrm{C}$.

It was found that before the North Crimean Canal closure, in June - October 2013, salinity in the Sivash increased from north to south from 10 PSU in the Tonkiy Strait area to 40 PSU in the south, in the area of the most remote stretch IV. The maximum freshening was experienced in the northwestern part of the bay, where the Dnieper water discharge point was located. Three years after the North Crimean Canal closure, water salinity in the northwest of the Sivash increased from 17 to 37 PSU.

The main supply of fDOM to the Sivash is provided by the flow of four rivers. This substance is deposited in the estuarine zone, forming concentration maxima of 52-57 QSU near the western coast of the bay. The mouth of the Pobednaya River is a natural marginal filter that traps up to $90 \%$ of fDOM contained in river water. The minimum concentration of the background field fDOM is typical for the northeastern part of the Sivash. In the Tonkiy Strait, as in the adjacent water area of the Sea of Azov, the fDOM content did not exceed 25-27 QSU.

A local maximum fDOM concentration 55 QSU at a low salinity of 11 PSU was recorded off the eastern coast of the Sivash in the isolated lake waters. A number of such lakes are located in the floodplains near the southern part of the Arabat Spit.

It is shown that salinity and fDOM concentration in the Sivash Bay waters are connected by a direct correlation dependence, with the coefficient $\mathrm{R}=0.61$, which is not typical of the marine environment. In the western part of the Sea of Azov adjacent to the Sivash, the correlation relationship $\operatorname{fDOM}(S)$ is inverse $(\mathrm{R}=-0.84)$, which is characteristic of coastal waters of the oceans and seas freshened by continental runoff.

The TSM concentration field is mainly determined by the shallowness of the Sivash Bay, the nature of the soil and the wind. Under conditions of low wind and calm weather, the bay waters are transparent and contain 1-2 mg/l of TSM. The field of this value reacts very quickly to wind intensification, and in moderate wind its concentration reaches $40-42 \mathrm{mg} / \mathrm{l}$.

\section{REFERENCES}

1. Constanza, R., de Groot, R., Sutton, P., van der Ploeg, S., Anderson, S.J., Kubiszewski, I., Farber, S. and Turner, K.R., 2014. Changes in the Global Value of Ecosystem Services. Global Environmental Change, 26, pp. 152-158. doi:10.1016/j.gloenvcha.2014.04.002

2. Kennish, M.J., 2001. Coastal Salt Marsh Systems in the U.S.: A Review of Anthropogenic Impacts. Journal of Coastal Research, 17(3), pp. 731-748. Available at: https://www.jstor.org/stable/4300224 [Accessed: 12 December 2021].

3. U.S. Fish and Wildlife Service, 1999. Coastal Salt Marsh. In: U.S. Fish and Wildlife Service, 1999. South Florida Multi-Species Recovery Plan. Atlanta, Georgia, pp. 3-553-3-596. 
Available at: https://www.fws.gov/verobeach/MSRPPDFs/SaltMarsh.pdf [Accessed: 12 October 2021].

4. $\quad$ Reed, D.J., 1990. The Impact of Sea-Level Rise on Coastal Salt Marshes. Progress in Physical Geography: Earth and Environment, 14(4), pp. 465-481. doi:10.1177/030913339001400403

5. Lefeuvre, J.-C., Bouchard, V., Feunteun, E., Grare, S., Laffaille, P. and Radureau, A., 2000. European Salt Marshes Diversity and Functioning: The Case Study of the Mont Saint-Michel Bay, France. Wetland Ecology and Management, 8(2-3), pp. 147-161. doi:10.1023/A:1008440401950

6. Ponizovskiy, A.M., 1965. Solyanyye Resursy Kryma [Salt Resources of Crimea]. Simferopol: Crimea, 163 p. (in Russian).

7. Stedmon, C.A., Markager, S. and Bro, R., 2003. Tracing Dissolved Organic Matter in Aquatic Environments Using a New Approach to Fluorescence Spectroscopy. Marine Chemistry, 82(3-4), pp. 239-254. doi:10.1016/S0304-4203(03)00072-0

8. Ji, Z.-G., 2017. Estuaries and Coastal Waters. In: Ji, Z.-G., 2017. Hydrodynamics and Water Quality: Modeling Rivers, Lakes, and Estuaries. Hoboken, NJ, USA: John Wiley \& Sons Inc.. Chapter 10, pp. 379-419. doi:10.1002/9781119371946.ch10

9. Sovga, E.E., Eremina, E.S. and D'yakov, N.N., 2018. System of the Ecological Monitoring in the Sivash Bay in the Modern Conditions. Ecological Safety of Coastal and Shelf Zones of Sea, (2), pp. 22-38. doi:10.22449/2413-5577-2018-2-22-38 (in Russian).

10. Stashchuk, M.F., Suprychev, V.A. and Khitraya, M.S., 1964. [Mineralogy, Geochemistry and Conditions for the Formation of Bottom Sediments of the Sivash]. Kiev: Naukova dumka, 174 p. (in Russian).

11. Rubakina, V.A., Kubryakov, A.A. and Stanichny, S.V., 2019. Seasonal and Diurnal Cycle of the Black Sea Water Temperature from Temperature-Profiling Drifters Data. Sovremennye Problemy Distantsionnogo Zondirovaniya Zemli iz Kosmosa, (5), pp. 268-281. doi:10.21046/2070-7401-2019-16-5-268-281 (in Russian).

12. Pugach, S.P. and Pipko, I.I., 2013. Dynamics of Colored Dissolved Matter on the East Siberian Sea Shelf. Doklady Earth Sciences, 448(1), pp. 153-156. https://doi.org/10.1134/S1028334X12120173

13. Kaiser, D., Konovalov, S., Schulz-Bull, D.E. and Waniek, J.J., 2017. Organic Matter along Longitudinal and Vertical Gradients in the Black Sea. Deep Sea Research Part I: Oceanographic Research Papers, 129, pp. 22-31. doi:10.1016/j.dsr.2017.09.006

14. Kari, E., Merkouriadi, I., Walve, J., Leppäranta, M. and Kratzer, S., 2018. Development of Under-Ice Stratification in Himmerfjärden Bay, North-Western Baltic Proper, and Their Effect on the Phytoplankton Spring Bloom. Journal of Marine Systems, 186, pp. 85-95. doi:10.1016/j.jmarsys.2018.06.004

15. Sasaki, H., Gomi, Y., Asai, T., Shibata, M., Kiyomoto, Y., Okamura, K., Morinaga, K., Nishiuchi, K., Hasegawa, T. and Yamada, H., 2013. Ocean Color Satellite-Derived Salinity Using Colored Dissolved Organic Matter (CDOM) in River-Influenced Region. Journal of the Japan Society for Marine Surveys and Technology, 25(2), pp. 13-18. doi:10.11306/jsmst.25.2_13

16. Seretti, A., Manca, B.B., Santinelli, C., Murru, E., Boldrin, A. and Nannicini, L., 2003. Relationships between Dissolved Organic Carbon (DOC) and Water Mass Structures in the Ionian Sea (Winter 1999). Journal of Geophysical Research: Oceans, 108(C9), 8112. doi:10.1029/2002JC001345

17. Hopkins, J., Lucas, M., Dufau, C., Sutton, M., Stum, J., Lauret, O. and Channelliere, C., 2013. Detection and Variability of the Congo River Plume from Satellite Derived Sea Surface Temperature, Salinity, Ocean Colour and Sea Level. Remote Sensing of Environment, 139, pp. 365-385. doi:10.1016/j.rse.2013.08.015

18. Lomakin, P.D., Chepyzhenko, A.I. and Chepyzhenko, A.A., 2016. Field of the Colored Dissolved Organic Matter Concentration in the Sea of Azov and the Kerch Strait Waters 
Based on Optical Observations. Physical Oceanography, (5), pp. 71-83. doi:10.22449/1573160X-2016-5-71-83

19. Lisitsyn, A.P., 1995. The Marginal Filter of the Ocean. Oceanology, 34(5), pp. 671-682.

20. Holeman, J.N., 1968. The Sediment Yield of Major Rivers of the World. Water Resources Research, 4(4), pp. 737-747. doi:10.1029/WR004i004p00737

21. Mantoura, R.F.C., Martin, J.-M. and Wollast, R., eds., 1991. Ocean Margin Processes in Global Change. Chichester: John Willey and Sons Ltd., 469 p.

About the author:

Pavel D. Lomakin, Senior Research Associate, Marine Hydrophysical Institute of RAS (2 Kapitanskaya St., Sevastopol, 299011, Russian Federation), Dr.Sci. (Geogr.), Professor, ResearcherID: V-7761-2017, Scopus Author ID: 6701439810, IstinaResearcherID (IRID): 18321047, p_lomakin@mail.ru

The author has read and approved the final manuscript.

The author declares that he has no conflict of interest. 